\title{
THE EFFECT OF PSYCHOLOGICAL INTERVENTION ON PERCEIVED PAIN IN CHILDREN UNDERGOING VENIPUNCTURE
}

\author{
Lucie Sikorova $^{a *}$, Petra Hrazdilova ${ }^{\mathrm{b}}$
}

\author{
a Department of Nursing and Midwifery, Faculty of Medicine, University of Ostrava, Czech Republic \\ ${ }^{b}$ Department of Pediatrics, University Hospital Olomouc \\ E-mail:lucie.sikorova@osu.cz
}

Received: January 12, 2011; Accepted: March 18, 2011

Key words: Pain Measurement/Venipucture/Randomized studies/Child/Nonpharmacological Interventions

Aims. The main objective of the study was to determine the effect of structured psychological intervention on the level of perceived pain in children undergoing venipuncture. A second goal was to investigate how pain behavior during venipuncture is affected by age, sex, previous number of venipunctures, the presence of parents during the procedure and reason for the venipuncture.

Methods. Children with indications for venipuncture aged 5-10 years, were randomly divided into a control group and an intervention group. The control group was prepared for the venipuncture routinely. Children in the intervention group were prepared according to prior structured psychological consultation. Perceived pain levels were assessed by the CHEOPS scale and the self report Wong and Baker faces pain rating scale.

Results. A significant difference in evaluated pain between the intervention group and the control group was found. The psychological intervention carried out by a nurse proved to lower pain levels from venipuncture as measured by the CHEOPS scale and evaluated using the self-report scale. A greater level of pain was found in children in the age group 5-7 years, in children where peripheral venous catheter was introduced and in children where the parents were present. Special consultation with the child one day before venipuncture reduced pain levels, especially in children below the age-category mentioned.

Consultation should be part of the standard of care for children with indications for venipuncture.

\section{INTRODUCTION}

Deutsch ${ }^{1}$ describes any rupture of the skin surface or entry into the body as an invasive procedure. Among unpleasant medical invasive procedures in childhood is venipuncture which is understood to be puncturing the vein with an injection needle. The goal of venipuncture can be to draw a blood sample or administer medication into the venous system ${ }^{2}$. Hana et al. ${ }^{3}$, Wong and Baker ${ }^{4}$, and Duff ${ }^{5}$ agree that repeated venipuncture is an especially stressful and painful experience for children while Bijttebier and Vertommen ${ }^{6}$ point out that venipuncture involving rough treatment, poor preparation or unbearable pain can have extensive effects that include anxiety, decreased pain threshold, reduced effects of analgesia for further procedures and avoidance of medical care. Dahlquist et al. ${ }^{7}$ adds that anxiety and fear during venipuncture also reduce cooperation from the child resulting in repeated attempts at carrying out the procedure. Conversely, among appropriate ways of reducing anxiety in hospitalized children are psycho pedagogical intervention programmes which increase the cooperation of the children as additional benefits ${ }^{8}$.

According to $\mathrm{McGrath}^{9}$, the behavior of children during invasive procedures is widely individual. and dependent on degree of perceived pain. Perception of pin is affected by emotional and situational factors ${ }^{9}$. It also varies according to age ${ }^{9-11}, \operatorname{sex}^{12-15}$, cognitive level ${ }^{9,16-18}$, tem- perament ${ }^{19,20}$, culture $^{8}$, parental support ${ }^{11,21-23}$ and other situational factors such as previous experience with painful exercise ${ }^{9}$, suppression/alleviation of pain using pharmacologic and nonpharmacologic means.

The use of non-pharmaceutical procedures to cope with pain behavior is, according to Jacobson ${ }^{24}$, less costly and most of these procedures can be administered by a nurse. They have been shown to reduce the perception of pain and make the interventionmore bearable ${ }^{25,26}$. The task of the nurse is to choose an appropriate method and ensure a comfortable environment for the intervention.

The objective of this study was to measure the effect of special consultation between child and nurse, on the level of perceived pain during venipuncture. Other goals were to explore the relation between perceivd pain during venipuncture and gender, age, number of previous venipunctures, the presence of parents during the procedure and reason for the venipuncture.

\section{MATERIALS AND METHODS}

The research group consisted of 60 children, 29 girls (48\%) and 31 boys (52\%), between the ages of 5 and 10 years old ( $M_{\text {age }} 7$ years $)$, average age 7.2 years who had been hospitalized between 1 October 2009 and 31 January 2010 in the pediatric ward at the Municipal Hospital of Ostrava. 


\section{Inclusion criteria}

Children with no current acute pain, no cognitive or severe physical disability, the ability to communicate in and understand the Czech language, consent of the parents for the child to take part in the research, health status that enabled working with the child, and no medication that could affect their psychological or physical state.

\section{Exclusion criteria}

Children whose venipuncture was postponed and children taking pain reducing medication.

The children were divided into a control or intervention group based on the numbers (odd and even) in the medical records. The research was approved by the Internal Review Board.

\section{Instruments}

A questionnaire for recording age, sex, experience of child with blood collection and self-report of pain. The children were given identification codes to ensure anonymity but provide the evaluator with orientation.

For evaluation of perceived pain during venipuncture, the CHEOPS scale was used - Children's Hospital of Eastern Ontario Pain Scale (CHEOPS), in the Czech language provided by Kalousová et al. ${ }^{27}$. CHEOPS is classified as an observation scale and was primarily developed to evaluate post-operative pain in small children. It can be used, however, to evaluate interventions for reducing pain and discomfort as well as for evaluating short and sharp pains $^{28}$. Its inter-rater reliability ranges from 0.90 to 0.99 $\left(\right.$ ref. $\left.^{29}\right)$. The scale includes six entries with an appropriate point evaluation focused on the character of crying (1-3 points), facial expressions ( $0-2$ points), verbal reaction (0-2 points), position of the body (1-2 points), touch (1-2 points), and position of the legs (1-2 points). Minimum score is 4 (no pain) and maximum is 13 (maximum pain).

Used for the self-report of pain during the procedure was the Wong and Baker faces pain rating scale which is represented by six animated faces whose expressions characterize the range of painfulness from the smiling "no pain" ( 0 points) to the crying face of "the worst pain" ( 5 points) (ref. $\left.{ }^{4}\right)$ translated into the Czech language ${ }^{27}$. The scale can be used for children from 3 to 18 years old ${ }^{30}$.

The researchers were ordinary members of the nursing team and thus did not arouse any increased attention among the children. The preparation of the children for scheduled venipuncture which is usually carried out in the ward between 6:15-6:45 in the morning, was done the day before close to the end of the practice hours of the administering doctor, mostly during afternoon hours. According to Khan and Weisman ${ }^{31}$, the time of preparation for the youngest of those of school age should not exceed $20 \mathrm{~min}$, and this condition was fulfilled. The doll Petruška was used to help prepare the child. The doll resembles the human body with wire frame and pliable arms and legs. The elbow bends are similar to a human elbow bend. This realistic aid was adapted to the reason for the procedure, ie.drawing a blood sample or introducing a peripheral venous catheter.
Consultations took place individually in the child's room as in the hospital, the room is the place of safety. The children were given only accurate and true information during the entire procedure and the interview was adapted to the age of the child and was simple and unambiguous.

The consultation on venipuncture consisted of four logically connected phases, which took place before, during and after the venipuncture.

In the first phase, the researcher created a feeling of confidence using conversation, and she got the child to interact. The interview focused on the experience of the child with venipuncture and on his/her interests. This information was later used during the venipuncture to distract the child according to the recommendations of McLaren and Cohen ${ }^{14}$. The first phase also included becoming acquainted with the child and informing him or her about the reason for the venipuncture.

In the second phase, the use of toys for showing the procedure and a direct demonstration of venipuncture on the doll Petruška were done with information on the reason for each step, e.g. necessity for applying the tourniquet - "When I tighten this rubber band on your arm, then I can see your veins better" - and disinfect the skin. The demonstration taught the child about any possible sensations: "The disinfection stinks just a little bit; it might also feel coldish on your skin, now you may feel a small sting". The emphasis was placed on educating them about appropriate behavior. „You cannot run away or kick the nurse, because then the blood collection will fail and she will have to sting you once again. You can cry if it helps you. You can even scream, as there is no need to be ashamed of it, but, please keep your hand still".

The third phase included training during the venipuncture on the child. Real needles were used with older children; for smaller children and less adroit children, only a pen holder without the tip was used. The researcher helped the child throughout the whole time and actively praised him or her.

In the fourth phase, the nurse showed the child the examination room where the venipuncture would proceed. The child was acquainted with the placement of the tools used for venipuncture and where he or she would sit during the procedure. Finally the child received a short picture story entitled "Taking Tom's blood, the boy who underwent venipuncture".

During the procedure, the researcher talked with the child about his or her interests, perhaps "leading" the child through the course of the procedure. The conversation during the procedure was always on an individual basis. After the conclusion of the venipuncture, the child was praised for his or her behavior. In the event that the child demonstrated significant resistance during the venipuncture, the researcher still found something positive in the child's behavior to boost his or her confidence for the future. "There you see, you can stand it and will cope better next time." Every child then received a medal for handling the venipuncture.

The intervention was always carried out by the same nurse who would be with the child during the venipunc- 
Table 1. Comparison of characteristics of the samples between the control and intervention groups (by Chi-square test, Fisher's exact test).

\begin{tabular}{|c|c|c|c|c|c|}
\hline \multirow[t]{2}{*}{ Characteristics } & \multicolumn{2}{|c|}{ Control group } & \multicolumn{2}{|c|}{ Intervention group } & \multirow[t]{2}{*}{$\mathrm{P}$} \\
\hline & Number & Percentage & Number & Percentage & \\
\hline \multicolumn{5}{|l|}{ Gender } & \multirow[t]{3}{*}{0.796} \\
\hline Male & 16 & 53.33 & 15 & 50.00 & \\
\hline Female & 14 & 46.67 & 15 & 50.00 & \\
\hline \multicolumn{5}{|l|}{$\begin{array}{l}\text { Previous experience } \\
\text { with venipuncture }\end{array}$} & \multirow[t]{6}{*}{$0.546^{*}$} \\
\hline First & 3 & 10.00 & 7 & 23.33 & \\
\hline Once - twice & 5 & 16.67 & 7 & 23.33 & \\
\hline $3-4$ times & 8 & 26.67 & 5 & 16.67 & \\
\hline $5-6$ times & 5 & 16.67 & 3 & 10.00 & \\
\hline More than 6 times & 9 & 30.00 & 8 & 26.67 & \\
\hline \multicolumn{5}{|l|}{ Reason for venipuncture } & \multirow[t]{3}{*}{$0.003 *$} \\
\hline Blood taking & 14 & 46.67 & 4 & 13.33 & \\
\hline $\begin{array}{l}\text { Implementation of peripheral } \\
\text { venous catheter }\end{array}$ & 16 & 53.33 & 26 & 86.67 & \\
\hline
\end{tabular}

*Fisher's exact test

Table 2. Comparison of pain scores (CHEOPS, self-report scale) between the control and the intervention groups (by Wilcoxon test).

\begin{tabular}{|l|l|c|c|c|c|c|c|c|}
\hline Pain score & Group & Number & Mean & Median & Min & Max & SD & P \\
\hline CHEOPS & Control & 30 & 9.33 & 10 & 5 & 13 & 2.36 & \multirow{2}{*}{0.005} \\
\cline { 2 - 10 } & Intervention & 30 & 6.87 & 6 & 4 & 12 & 2.16 & 0.039 \\
\hline \multirow{2}{*}{ Self-report } & Control & 30 & 1.97 & 2 & 0 & 5 & 1.71 & 1.57 \\
\cline { 2 - 10 } & Intervention & 30 & 1.13 & 1 & 0 & 5 & \multirow{2}{*}{0} \\
\hline
\end{tabular}

SD Standard deviation

Table 3. Comparison of the final score of the assessment of pain (CHEOPS) between control and intervention groups in age subgroups (by Wilcoxon test).

\begin{tabular}{|l|l|c|c|c|c|c|c|}
\hline Group & Subgroup & Number & Mean & SD & Min & Max & P \\
\hline \multirow{2}{*}{ Control } & Younger & 17 & 11.06 & 1.68 & 8 & 13 & 0.005 \\
\cline { 2 - 9 } & Older & 13 & 8.46 & 2.37 & 5 & 13 & 0.005 \\
\hline \multirow{2}{*}{ Intervention } & Younger & 18 & 7.94 & 2.13 & 5 & 12 & 6 \\
\cline { 2 - 8 } & Older & 12 & 5.25 & 0.75 & 4 & 6 \\
\hline
\end{tabular}

SD Standard deviation 
ture and assisting the doctor to introduce the peripheral venal catheter. Immediately after the venipuncture, a second researcher recorded the observed behavior of the child using the CHEOPS. Within 5 min after the venipuncture, the researcher asked the child to evaluate the painfulness of the procedure using the described selfreport of pain ${ }^{27}$.

\section{Data analysis}

The sample characteristics (age, gender, number of experiences with venipuncture) were described using descriptive statistics - medians, means and standard deviation. Chi-squared and Fisher's exact tests $(p=5 \%)$ were used to evaluate these data and the data from the presence absence of parents for the two groups. For testing the differences in CHEOPS scale and self-report results the non parametric Wilcoxon test was used. The level of the statistical significance was $p=0.05$. The Spearman Rank coefficient was used to test the correlation between the CHEOPS and self-report scale.

\section{RESULTS}

The parents of 20 children (33\%) were present, those for $40(67 \%)$ were not. The number of previous venipunctures was 0 to 5 .

From the Chi-squared and Fisher's exact tests, there were no statistically significant differences between the groups for any parameter with the exception of reason for venipuncture - blood taking was more frequent in the control group while peripheral venous catheter was more frequent in the intervention group (Table 1).

The correlation coefficient between CHEOPS and self-report scale using the Spearman test was $r_{s}=0.603$.

A statistically significant difference was found ( $p=$ 0.005 ) for the CHEOPS scale results between groups (Table 2). Children in the intervention group $n=30$ (50\%) achieved on average a lower final CHEOPS score $(6.87: \mathrm{SD}=2.16)$ than children in the control group $(9.93: \mathrm{SD}=2.36) .26 / 30$ children in the control group achieved a final score above 6 points which indicates the presence of pain behavior. In contrast, only 13/30 children ( $50 \%$ fewer) in the intervention group achieved a final score above 6 points.

There was a significant difference between groups ( $p$ $=0.039$ ) for the self-report Wong-Baker faces pain rating scale (Table 2). Only 8/30 children in the control group (27\%) evaluated venipuncture on the faces pain rating scale as "did not hurt", while 14 children (47\%) in the intervention group gave it the same rating, representing nearly half of the group.

There was a statistically significant difference in CHEOPS scores for both groups divided into younger ( 5 to 7 years) and older children ( 8 to 10 year). The younger group had significantly higher values CHEOPS than the older group ( $p=0.005$ for both groups).

There was no statistically significant difference between boys and girls on the CHEOPS scale.
Dividing the groups into those with a larger and smaller number of venipunctures in the past, showed there was no statistically significant difference in CHEOPS scores for either group.

There was a significant difference in CHEOPS score between children undergoing venipuncture in to introduce a peripheral venal catheter and those undergoing venipuncture only for the purpose of drawing a blood sample using a standard needle but only for the intervention group $(\mathrm{p}=0.007)$.

There was a significant difference in CHEOPS score in the intervention group ( $p=0.030)$ but not the control group $(p=0.079)$ between children attended by their parents during venipuncture $n=16(53 \%)$ and children unattended by their parents during the procedure $n=14$ ( $47 \%$ ) in the intervention group. The attended group had a higher CHEOPS score $(10.6: \mathrm{SD}=1.9)$ than the unattended children $(7.3: \mathrm{SD}=2.4)$.

\section{DISCUSSION}

Venipuncture can be classified as a minor invasive procedure but for children it is ccompanied by fear and anxiety. For this reason, it is important to provide them with proper care. The results show that children in the intervention group who had been prepared for the procedure using education, demonstration on a doll, distracting the child during the procedure, and giving them a reward, reported lower pain behavior during the actual venipuncture than children in the control group who received standard treatment. We found statistically significant differences in CHEOPS scores, and the self-report pain scale between the groups.

We also examined the effect of age on pain pain behavior during venipuncture. $\mathrm{Craig}^{32}$, states that the intensity of pain behavior during invasive procedures decreases with the age of the child. For this reason, we expected to find a difference in pain behavior between the groups of younger and older children and this supposition was confirmed. Younger children demonstrated relatively more pain behavior than older children. Although several studies report differences in expressions of pain during invasive procedures between girls and boys (Gullone ${ }^{33}$, Kuba and Quinones-Jenab ${ }^{34}$ ) our intervention did not confirm this difference.

It has been reported that the pain of introducing a peripheral catheter into the vein increases with diameter of needle $\mathrm{e}^{35}$. The pain perceived during the cannulation according to this research, varies according to the location of the puncture in the upper limb. In our study, a needle of diameter $21 \mathrm{G}$ was used for the venipuncture for the purposes of drawing a simple blood sample. For determining the peripheral venal course, needles $22 \mathrm{G}$ and $24 \mathrm{G}$ were used (smaller diameters are only used in the ward in the special case where the venous system of the child has collapsed). We therefore surmised that the introduction of a peripheral venal cannula would be more painful than venipuncture with a thinner needle on aver- 
age. Drawing the blood sample mostly took place from veins in the arm at the bend of the elbow; for introducing a peripheral venal catheter, the veins in the forearm and the back surface of the hand were mostly used. The location of the puncture could therefore also have significantly contributed to greater pain during venipuncture. The children in our research undergoing venipuncture for the purposes of introducing a peripheral venal catheter demonstrated a greater average pain score than children undergoing venipuncture for the purposes of drawing a blood sample using a standard needle.

Fitzgerald and Beggs ${ }^{36}$, state that previous experience with pain can affect behavior during future painful stimuli. Our study showed no statistically significant differences in the behavior of children in relation to number of venipuncture procedures in the anamnesis. The results could have been influenced by the fact that we were not concerned whether previous experience with venipuncture had been negative for the child.

The significantly higher score for children in the intervention group who were attended by their parents compared to those who were not, was suprising. Instructing the parents had positive results on the behavior of children during the procedure in the research of Broome ${ }^{37}$. Since the parents in our study were not informed how to support their children during venipuncture, this may have affected the results. In the control group there was no significant difference in pain levels among attended and unattended children. This may have been due to the low number of attended children.

\section{CONCLUSION}

The study showed that special consultation between nurse and child regarding venipuncture had positive effects on reducing perceived pain during the intervention. Children between five to seven years old experienced pain more intensely, than children between eight to ten and children whose venipucture was for peripheral venous catheter experienced more pain than those for undergoing blood withdrawal. If the parents are not educated on how to encourage and support their child during venepuncture, they might increase the perceived pain level in their children. Perceived pain does not depend on number of previous venipunctures or no experience of it it. We found no difference between boys and girls in perceived pain.

\section{Practice Implications}

Based on the positive results, we recommend proper preparation of each child individually through appropriate psychological interventions such as explanation, demonstration and story, especially for children younger than seven years and for introducing a continuous venal catheter. The results should serve as a source of information for comparison with other studies.

\section{REFERENCES}

1. Deutsch LM. Medical records for attorneys. Philadelphia: Ali-Aba, 2001.

2. Vokurka M, Hugo J. Practical dictionary of medicine. Praha: Maxdorf, 2008.

3. Yoo H, Kim S, Hur HK, Kim HS. The effects of an animation distraction intervention on pain response of preschool children during venipuncture. Appl Nurs Res. 2009 [Epub ahead of print] doi:10.1016/j.apnr.2009.03.005

4. Wong DL, Baker CM. Pain in children: comparison of assessment scales. Okla Nurse 1988; 33:8.

5. Duff AJA. Incorporating psychological approaches into routine paediatric venepuncture. Arch Dis Child 2003;88:931-37.

6. Bijttebier P, Vertommen H. The Impact of previous experience on children's reactions to venepuncture. J Health Psychol 1998;3:3946.

7. Dahlquist LM, Busby SM, Slifer KJ, Tucker CL, Eischen S, Hilley L, Sulc W. Distraction for Children of Different Ages Who Undergo Repeated Needle Sticks. J Pediatr Oncol Nurs 2002;19:2234.

8. Lipton JA, Marbach JJ. Ethnicity and the pain experience. Soc Sci Med 1984;19:1279-98.

9. McGrath PA. Pain in children: nature, assessment, and treatment. New York: Guilford Press, 1990.

10. Franck LS, Greenberg CS, Stevens B. Pain assessment in infants and children. Pediatr Clin North Am 2000;47:487-512.

11. Chambers CT, Craig KD, Bennett SM. The impact of maternal behavior on children's pain experiences: An experimental analysis. J Pediatr Psychol 2002;27:293-301.

12. Unruh AM. Gender variations in clinical pain experience. Pain 1996;65:123-67.

13. Roth-Isigkeit A, Thyen U, Raspe HH, Stöven H, Schmucker P. Reports of pain among German children and adolescents: an epidemiological study. Acta Pediatr 2004;93:258-63.

14. McLaren JE, Cohen LL. Interventions for paediatric procedure related pain in primary care. Pediatr Child Health 2007;12:111-16.

15. Tak JH, Van Bon WHJ. Pain-and distress-reducing interventions for venepuncture in children. Child Care Health Dev 2006;32:257-68.

16. Mareš J. Child and the pain. Praha: Grada, 1997.

17. Fitzgerald M. The development of nociceptive circuits. Nat Rev Neurosci 2005;6:507-20.

18. Carr TD, Lemanec KL, Amstrong FD. Pain and fear ratings: Clinical implications of age and gender differences. J Pain Smptom Manage 1998;15:505-13.

19. Lee LW, White-Traut RC. The role of temperament in pediatric pain response. Issues Compr Pediatr Nurs 1996;19:49-63.

20. Werneck H, Rollett B. Temperamententwicklung. In: Rollett, B., Werneck H. Klinische entwicklungspsychologie der familie. Hogrefe Göttingen: Hogrefe, 2002, p. 372.

21. Blount RL, Cohen LL, Frank NC. The Child-Adult Medical Procedure Interaction Scale-Revised: An Assessment of Validity. J Pediatr Psychol 1997;22:73-88.

22. Mareš J, Marešová J. Rodiče jako posuzovatelé dětské bolesti. Pain 2000;3:135-9.

23. Robinson JO, Alverez JH, Dodge JA. Life events and family history in children with recurrent abdominal pain. J Psychosom Res 1990;34:171-81.

24. Jacobson AF. Intradermal normal saline solution, self-selected music, and insertion difficulty effects on intravenous insertion pain. Heart Lung 1999;28:114-22.

25. Wang ZX, Sun LH, Chen AP. Efficacy of non-pharmacological methods of pain management in school-age children receiving venipuncture in a pediatric department: A randomized controlled trial of audiovisual distraction and routine psychological intervention. Swiss Med Wkly 2008;138:579-84.

26. Movahedi AF, Rostami S, Salsali M, Keikhaee B, Moradi A. Effect of local refrigeration prior to venipuncture on pain related responses in school age children. Aus J Adv Nurs 2006;24:51-5.

27. Kalousová J, Rousková B, Pachmannová D, Stýblová J. Bolest u dětí: hodnocení a některé způsoby léčby. Pediatrics for praxis 2008;9:7-11. 
28. Van-Cleve L, Johnson L, Pothier P. Pain responses of hospitalized infants and children to venipuncture and intravenous cannulation. J Pediatr Nurs 1996;11:161-8.

29. King SN, Ellis DA, Frey MA. Assessing children's well-being Mahwah: Taylor \& Francis, 2009. p. 39.

30. Cohen LL. Behavioral approaches to anxiety and pain management for pediatric venous access. Pediatrics 2008;122:134-9.

31. Khan KA, Weisman SJ. Nonpharmacologic pain management strategies in the pediatric emergency department. Clin Pediatr Emerg Med 2007;8:240-47.

32. Craig KD. Pain in infants and children: Sociodevelopmental variations on the theme. In: Giamberardino MA, ed. Pain 2002 - An Updated Review. Refresher Course Syllabus. (10th ed.), World Congress on Pain, San Diego, CA. Seattle, IASP Press, 2002;30514.
33. Gullone E. The development of normal fear: A century of research. Clin Psychol Rev 2000;20:429-51.

34. Kuba T, Quinones-Jenab V. The role of female gonadal hormones in behavioral sex differences in persistent and chronic pain: Clinical versus preclinical studies. Brain Res Bull 2005;66:179-88.

35. Steinbrook RA, Hughes N, Fanciullo G, Manzi D, Ferrante F. Effect of alkalinization of lidocaine on the pain of skin infiltration and intravenous catheterization. J Clin Anesth 1993;5:456-8.

36. Fitzgerald M, Beggs S. The neurobiology of pain: Developmental aspects. Neuroscientist 2001;7:246-57.

37. Broome ME. Helping parents support their child in pain. Pediatr Nurs 2000;26:315-17. 